\title{
RANCANG BANGUN SISTEM PENGHITUNGAN HEART RATE MENGGUNAKAN SENSOR FINGER
}

\author{
Ria Eksaktania \\ Teknik Elektro, Fakultas Teknik, Universitas Hasyim Asy’ari, Email : eksaktania_ria@yahoo.co.id \\ Tri Rijanto \\ Teknik Elektro, Fakultas Teknik, Universitas Hasyim Asy’ari, Email : tririjanto.unesa@ac.id \\ Elly Indahwati \\ Teknik Elektro, Fakultas Teknik, Universitas Hasyim Asy’ari, Email : ellyindahwati31@ gmail.com
}

\begin{abstract}
Abstrak
Pembuatan modul heart rate bertujuan untuk memperoleh informasi akurasi modul dibandingkan dengan alat ukur standart (Pulse Oxymetri). Sistem kerja yang digunakan menggunakan sensor finger dan berbasis Arduino Uno yang hasilnya ditampilkan pada LCD. Penelitian ini menggunakan metode dengan cara membandingkan hasil penghitungan heart rate pada modul dengan alat ukur standart (pulse oxymetri) yang dilakukan pada 5 responden, setiap responden dilakukan 5 kali pengukuran. Pengukuran dilakukan dengan cara bersamaan antara modul dan pembanding (pulse oxymetri) pada jari telunjuk kanan dan kiri menggunakan sensor finger. Hasil penelitian ini menunjukkan alat ini laik pakai dengan pengukuran pembandingan menggunakan Pulse Oxymetri sebanyak 5 kali dengan 5 responden dengan hasil rata-rata error $0,38 \%$.
\end{abstract}

Kata Kunci : Heart Rate, Sensor Finger, Arduino Uno

Abstract

Making heart rate module aims to obtain information module accuracy compared to standard gauge (Pulse Oxymetri). Work system which used using finger and sensor-based Arduino Uno which results are displayed on the LCD. This research uses the method by means of comparing the results of calculating heart rate on the module with the standard gauge (pulse oxymetri) conducted in 5 respondents, each of the respondents was conducted 5 times of measurement. The measurement is done by way of a coexisting between module and checklists (pulse oxymetri) on the index finger of the right and left using the finger sensor. The results of this study showed this tool be eligible to use the benchmarking measurement using Pulse with Oxymetri as much as 5 times by 5 respondents with an average error of results of $0.38 \%$.

Key Words : Heart Rate, Finger Sensor, Arduino Uno

\section{PENDAHULUAN}

Heart rate merupakan jumlah detak jantung per satuan waktu, dinyatakan sebagai denyut per menit (bpm). Pengukuran denyut jantung digunakan oleh para profesional medis untuk membantu dalam diagnosis dan palacakan kondisi medis (Sharief, 2011). Detak jantung manusia normal berkisar antara 60-100 denyut per menit (Syaifudin, 2011). Denyut jantung yang lebih rendah saat istirahat menunjukkan bahwa fungsi jantung lebih efisien dan kebugaran kardiovaskularnya lebih baik. Apabila detak jantung melebihi dari 100 denyut per menit, orang tersebut diindikasikan menderita kelainan jantung tachycardia. Sebaliknya apabila detak jantung kurang dari 60 denyut per menit, orang tersebut diindikasikan menderita kelainan jantung bradycardia (Nadya, 2016).

Penggunaan sensor elektroda pada heart rate untuk mendeteksi sinyal jantung telah banyak digunakan. Namun pada penggunaanya kurang efisien pada saat digunakan pasien. Pada umumnya lokasi khusus adalah jari dan daun telinga, sedangkan pada bayi adalah kaki atau telapak tangan dan ibu jari. Untuk membuat pendeteksi heart rate yang menggunakan finger sensor lebih mudah dan efisien karena lokasi penggunaanya dijepitkan pada jari telunjuk. Alat pendeteksi heart rate digunakan untuk pasien dewasa (18 - > 40 tahun). Prinsip sensor ini didasarkan pada infrared dan photodioda yang mendeteksi aliran darah. Penggunaan suatu cahaya dan infrared melalui lokasi khusus yang tembus cahaya dan memiliki aliran darah yang baik.

Dalam dunia kedokteran alat standart yang digunakan untuk mendeteksi detak jantung adalah Pulse oxymetri. Pulse oxymetri adalah alat yang digunakan untuk mengetahui kadar oksigen dalam darah dan untuk memeriksa kondisi kesehatan jantung. Sehubungan dengan itu, perlu dirancang alat dengan judul "Rancang Bangun Sistem Penghitungan Heart Rate Menggunakan Sensor Finger". Di mana hasil dari pengukuran akan ditampilkan pada LCD karakter. 


\section{METODE}

Metode yang digunakan dalam penelitian ini adalah metode eksperimen yaitu infrared dan photodiode difungsikan sebagai pengirim dan penerima cahaya yang dihasilkan logika. Langkah perancangan menggunakan perangkat keras (hardware) dan perangkat lunak (software). Blok diagram sistem dan diagram alir rancangan dalam penelitian ini sebagai berikut:

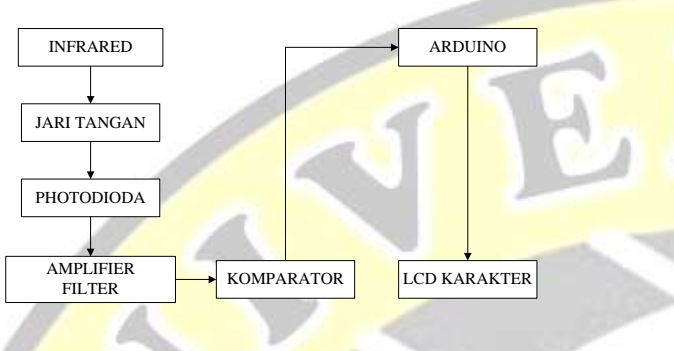

Gambar 1. Blok Diagram Perencanaan Sistem Heart

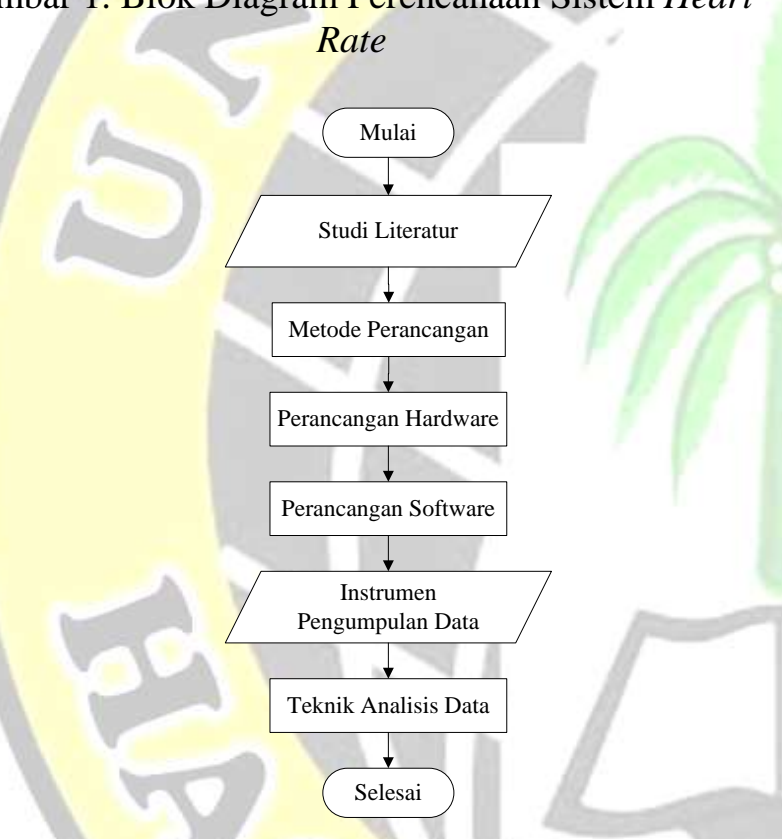

Gambar 2. Diagram Alir Rancangan Penelitian

Rangkaian skematik yang digunakan dalam penelitian ini meliputi rangkaian finger sensor dan rangkaian pengondisi sinyal.

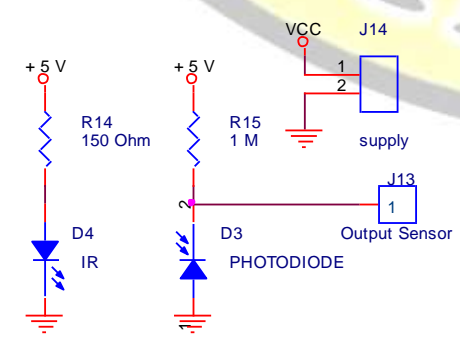

Gambar 3. Rangkaian Finger Sensor

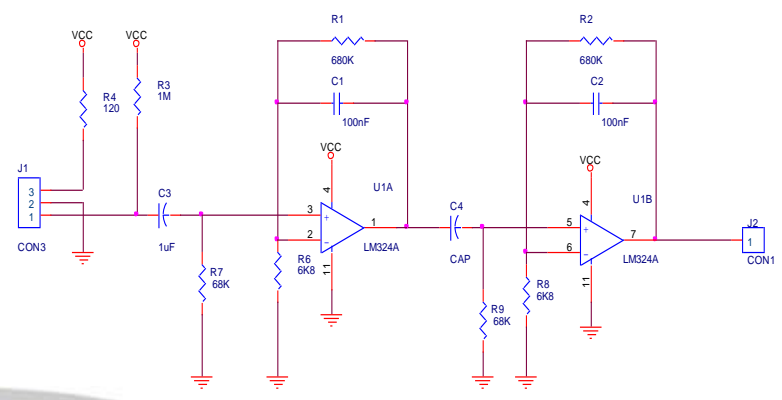

Gambar 4. Rangkaian Pengondisi Sinyal

Pada saat sensor bekerja, infrared sebagai sumber cahaya dan photodiode sebagai penerima. infrared memancarkan cahaya dengan panjang gelombang $980 \mathrm{~nm}$ pada jari tangan, kemudian cahaya menembus jari tangan dan diterima oleh photodiode. Cahaya yang diterima dipengaruhi oleh kepekatan darah yang dipompa oleh jantung. Resistor $120 \mathrm{Ohm}$ (R4) berfungsi sebagai resistor pengaman infrared, sedangkan resistor $1 \mathrm{M}$ (R3) digunakan sebagai pembagi tegangan terhadap photodiode pada rangkaian sensor finger sehingga menghasilkan tegangan yang berubah-ubah dan membuat output dari Photodiode membentuk sinyal AC. Sinyal tersebut belum bisa dihitung frekuensi maupun amplitudonya. Sinyal tersebut masuk pada rangkaian Blok DC 1 uf (C3) dengan resistor 68K (R7) yang dinamakan filter pasif berfungsi untuk menekan tegangan DC pada GND, sehingga sinyal yang diloloskan hanya sinyal AC yang akan dikuatkan dan di filter. Sinyal AC tersebut masuk pada IC LM324 yang dimana sinyal tersebut akan dikuatkan menggunakan penguatan Non Inverting dengan Gain 101 x sebanyak 2 kali dan akan difilter dengan menggunakan Low Pass Filter dengan Cut Off 2,34 $\mathrm{Hz}$.

\section{HASIL DAN PEMBAHASAN}

Berdasarkan hasil pembandingan antara modul dan pulse oxymetri (pembanding) didapatkan hasil yang berbeda/ adanya selisih nilai. Nilai error yang didapat paling besar adalah 1,1933\% dan paling kecil adalah $0,01 \%$.

Tabel 1. Hasil Pengukuran Heart Rate pada

\begin{tabular}{|c|c|c|c|c|c|c|c|c|c|c|c|}
\hline \multirow{2}{*}{ No. } & \multirow{2}{*}{ Responden } & \multirow{2}{*}{ Alat } & \multicolumn{5}{|c|}{ Pengukmran } & \multirow{2}{*}{ Mean } & \multirow{2}{*}{ STD } & \multirow{2}{*}{$\mathrm{Da}_{\mathrm{a}}$} & \multirow{2}{*}{ QHErr } \\
\hline & & & $x 1$ & $x_{2}$ & $x_{3}$ & $X_{4}$ & $x 5$ & & & & \\
\hline \multirow{2}{*}{1} & \multirow{2}{*}{ Dinhas } & Penbi & 54 & 59 & $B 6$ & 56 & 57 & 86,4 & 1,81 & 0,81 & $*$ \\
\hline & & Modul & 54 & Ss & 54 & 58 & s8 & 86.6 & 2,99 & 0,16 & 0.23 \\
\hline \multirow{2}{*}{2} & \multirow{2}{*}{ Nur Fauzi } & Pemban & 90 & 93 & 92 & 93 & 93 & 92.2 & 1,30 & 0,58 & - \\
\hline & & Modul & 92 & 92 & 92 & 92 & 92 & 92 & 0 & D & 0.21 \\
\hline \multirow{2}{*}{3} & \multirow{2}{*}{ Didik } & Pemban & 81 & 84 & 85 & 83 & 85 & 84.2 & 2,58 & 1.15 & $=$ \\
\hline & & Modul & 50 & 54 & 54 & 84 & 58 & S4 & 2,82 & 1,26 & 0,23 \\
\hline \multirow{2}{*}{4} & \multirow{2}{*}{ Denuny } & Pemban & 54 & so & 55 & 54 & 56 & 83,5 & 2,25 & 1,01 & 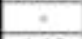 \\
\hline & & Modul & 82 & 50 & 54 & 84 & 84 & 82.8 & 1.78 & 0,8 & 1.19 \\
\hline \multirow{2}{*}{5} & Ahmad & Pemben & 85 & 84 & 85 & 85. & 82 & 84.2 & 1,43 & 0,64 & 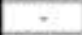 \\
\hline & Suntoso & Modul & 84 & 84 & 54 & 84 & 50 & 83,2 & 1,78 & 0.5 & 0.01 \\
\hline
\end{tabular}


Pengukuran heart rate dilakukan sebanyal 5 kali pada setiap responden dengan menggunakan modul dan alat pembanding (pulse oxymetri) yang dilakukan secara bersamaan pada jari tangan kanan dan kiri. Setelah dilakukan pengukuran maka akan didapatkan nilai error pada modul dengan pembanding (pulse oxymetri).

Grafik rata-rata pengukuran modul dengan pembanding (pulse oxymetri) menunjukkan bahwa masih adanya selisih. Gambar grafik sebagai berikut:

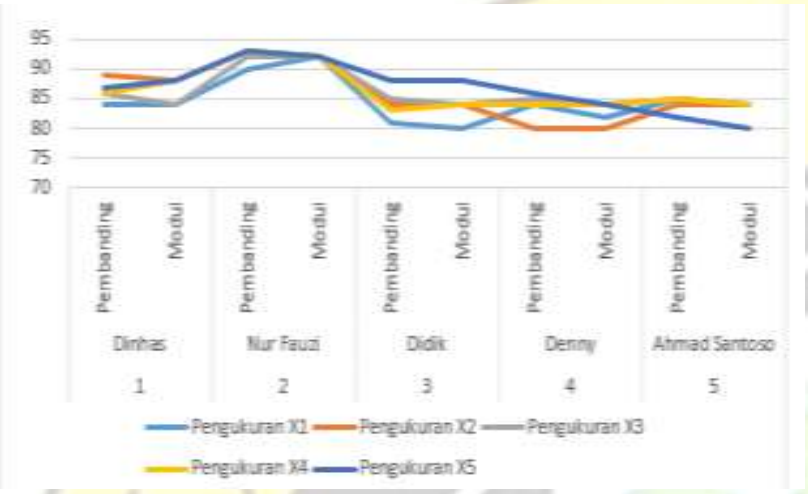

Gambar 5. Grafik Rata-rata Pengukuran Modul dengan Pembanding (Pulse oxymetri)

Grafik pada Gambar diatas adalah perbandingan nilai rata-rata pengukuran pembanding dengan ratarata pengukuran modul. Pada grafik menunjukkan masih adanya selisih antara alat pembanding dengan modul. Hal-hal yang mempengaruhi hasil pengukuran heart rate antara modul dengan pembanding (pulse oxymetri) antara lain:

- Kondisi yang tenang, karena apabila ada pergerakan terutama pada jari akan berpengaruh pada sensor .

- Pada saat dilakukan pengambilan data pengkuran diharapkan menunggu sampai kondisi responden stabil.

Gambar modul heart rate dan pembanding (pulse oxymetri) dapat dilihat pada Gambar di bawah ini:

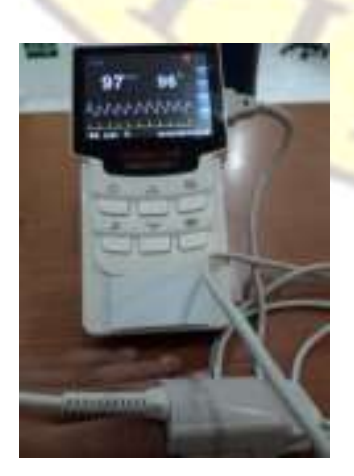

Gambar 6. Pulse Oxymetri (Pembanding)

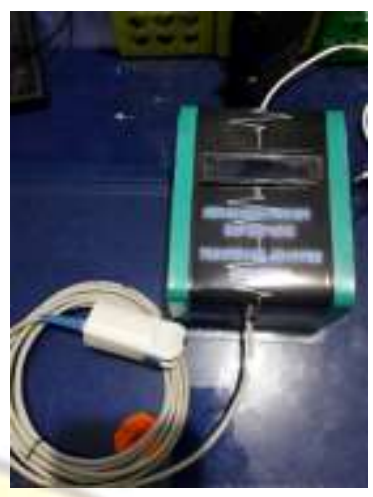

Gambar 7. Modul Heart Rate Finger Sensor

\section{Pembahasan Kinerja Keseluruhan}

Pada responden 1, didapatkan hasil error pengukuran sebesar $0,231 \%$. Pada responden 2, didapatkan hasil error pengukuran sebesar 0,2169\%. Pada responden 3, didapatkan hasil error pengukuran sebesar $0,2375 \%$. Pada responden 4 didapatkan hasil error pengukuran sebesar 1,1933\%. Pada responden 5 didapatkan hasil error pengukuran sebesar $0,01 \%$.

Hasil pengukuran menunjukkan adanya nilai error, karena dilakukan pembandingan langsung dengan pulse oximetry yang sudah memiliki sertifikasi kalibrasi. Darah setelah keluar dari jantung akan melewati banyak jaringan dan otot-otot yang akan mempengaruhi aliran darah pada jari telunjuk. Kondisi tubuh setiap pasien berbeda-beda, pasien dengan keadaan tubuh yang normal, aliran darahnya akan mengalir dengan normal artinya jumlah denyut jantung dengan aliran darah sama di setiap titik pengukuran. Tetapi jika kondisi pasien yang tidak normal, seperti keadaan tubuh yang kurang berolahraga, terdapat otot-otot yang kaku maka aliran darah akan terhambat sehingga antara jumlah denyut jantung dan aliran darah terutama di daun telinga akan mengalami perbedaan hasil.

\section{KESIMPULAN}

Setelah melakukan proses pembuatan dan studi literatur perencanaan, percobaan, pengujian dan pendataan alat dengan perbandingan, maka dapat disimpulkan bahwa heart rate dapat dideteksi menggunakan sensor finger dengan baik. Setelah dilakukan pengukuran dengan pembandingan alat pulse oxymetri didapatkan nilai error rata-rata pengukuran heart rate yaitu sebesar $0,38 \%$. Penguatan pada rangkaian sebesar 101x sebanyak 2x penguatan, namun kenyataannya sekitar 100x penguatan. Software yang telah dibuat dapat bekerja sesuai dengan urutannya, terbukti dengan modul dapat medeteksi heart rate. 


\section{DAFTAR PUSTAKA}

Dyah Khoirunisa. 2013. Monitoring BPM dan Suhu

Tubuh menggunakan Wireless berbasis Mikrokontroller Atmega8, Jurusan Teknik Elektromedik - Poltekkes Kemenkes, Surabaya.

Guruh, Bambang., Ariswati, Hergumiwang. 2011. Jurnal Teknokes, Ikatemi Jawa Timur dan Jurusan Teknik Elektromedik Poltekes Surabaya, 6, 2, 434-474.

Nadya Nezwa. 2016. Wireless Monitoring BPM dan Suhu Dilengkapi Nurse Call Berbasis PC, Jurusan Teknik Elektromedik-Poltekkes Kemenkes, Surabaya.

Raden Duta Abadi. 2016. Monitoring Heart Rate, Respiration Rate di lengkapi Sensor Suhu ke Personal Komputer menggunakan Bluettoth, Jurusan Teknik Elektromedik-Poltekkes Kemenkes, Surabaya.

Sharief, F- Babiker., Abdel-Khair, L, E., Elbasher, S, M., 2011, Microcontroller Based Heart Rate Monitor using Fingertip Sensors, 1, 2, 47-51.

Syaifudin. 2011. "Alat Menghitung BPM Dengan Menggunakan Finger Sensor Berbasis Mikrokontroller AT89S51". Vol. 6 (2): hal 434-437.

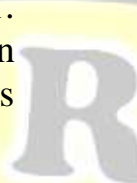

